\title{
Die ware en valse kerk \\ volgens artikels 28 en 29 van die NGB
}

\author{
V E d'Assonville \\ Potchefstroomse Universiteit vir CHO
}

\begin{abstract}
The true and false church according to articles 28 and 29 of the Confessio Belgica

The concept 'true and false church' date back to the sixteenth century; even so its meaning is obscure in the twentieth century. The reformers based their differentiation between these two terms on the Bible. According to the Confessio Belgica, the true and false church are differentiated by the symbols of preaching, the sacraments and the implementation of church discipline. Articles 28 and 29 , which deal specifically with this matter, are therefore presented in this paper.
\end{abstract}

Ons moet op geen enkele manier daaraan twyfel nie, dat oral waar ons sien dat God se Woord suiwer gepreek en aangehoor word en die sakramente soos Christus hulle ingestel het, bedien word, daar 'n kerk van God is.

(Calvyn Institusie IV, i:9; my vertaling)

\section{PROBI FEMSTEI $\perp$ ING}

Die begrippe 'ware kerk' en 'valse kerk' bly steeds onder teoloë aanvegbaar. Selfs in Gereformeerde kerke (hulle wat arts 28 \& 29 van die NGB handhaaf) is daar sedert die Reformasie in die sestiende eeu nog geen eenstemmigheid oor die interpre-

- Hierdie artikel is corspronklik geskrywe met die oog op publikasie in HTS. Daarna het dit in in populere verkorte vorm in die bundel 'Kerkwees as getuienis in SA vandag' (uitgegee deur die Potchefstroomse Tcologiese Publikasies, 1991) verskyn. 
tasie van hierdie terme nie. De Heraut, die bekende blad van dr A Kuyper, verklaar op 'n keer 'dat niet vergeten mag worden, dat de Schrift te weinig positieve gegevens over de valse kerk biedt om zuiver schriftuurlike termen op te nemen' (De Heraut 2092, aangehaal deur G Visée in Dienst:153w).

As hierdie oppervlakkige stelling waar sou wees, dan het die NGB in artikels 28 en 29 te veel gesê. Met watter reg kan die Gereformeerde kerke dan nog aan hierdie artikels gebind wees? Maar dit is nie al nie. Kom die belydenis oor die merktekens (die begrip 'merktekens' - 'n beter vertaling van die oorspronklike 'notae' word gebruik i p v 'kenmerke', omdat 'kenmerke' te veel verwar word met 'eienskappe') van die ware en valse kerke dan nie ook in gedrang nie? Hier word gepoog om 'n antwoord aan te bied.

\section{'N KORTPAD DEUR DIE GESKIEDENIS VAN DIE SES TIENDE-EEUSE REFORMASIE}

Luther beweer in sy geskrif Teen Hans Wors (1541) dat daar van die begin van die wêreld tot aan die einde twee kerke sal wees. Augustinus noem hulle Kain en Abel. Ook verbied Christus sy volgelinge om die valse kerk te aanvaar en Hy onderskei twee kerke, naamlik die ware en die valse kerk volgens Matteus 7:15 (Luther 1830, vol 26:11, 12). Die volledigste uiteensetting oor die merktekens van die ware en valse kerke word gevind in Luther se geskrif ' $V$ an konsilies en kerke' (1539). Dit behels die suiwer prediking, die regte gebruik van die sakramente en die hantering van die sleutelmag volgens Matteus 18:15 en 16 (Luther 1830, vol 25:359-363). Ook Melanchton en Bullinger gee duidelike uiteensettings oor die ware en valse kerke met bewysplekke uit die Bybel (Polman sa:315-316).

Van al die Hervormers is Calvyn oor hierdie onderwerp die duidelikste en breedvoerigste. In die vierde boek van sy Institusie wy hy 'n hele hoofstuk aan 'n vergelyking van die valse met die ware kerk (Calvyn Institusie IV, ii:1-12). Vir hom is die valse kerk ten eerste die Rooms-Katolieke Kerk. Hy beskou dit steeds as 'n kerk, maar 'in plaas van die diens van die Woord bedryf hulle skole van goddeloosheid en 'n vuil versameling van allerhande dwalings. Daarom is hulle eintlik geen kerke meer nie en bly daar geen kenteken meer oor om hulle van die wettige vergadering van gelowiges van die Turke se byeenkomste te onderskei nie' (Calvyn Institusie IV, ii: 10; my vertaling).

Calvyn wil nie graag die Rooms-Katolieke Kerk as kerk erken nie. Tog stel hy:

Hoewel ons dus nie die titel van kerk eenvoudig aan die pousgesindes wil toestaan nie, loën ons dit nie dat daar tog by hulle kerke is nie; maar ons stry vir die ware en wettiglike inrigting van die kerk, wat in 
die gemeenskap van die sakramente, wat 'n teken van die belydenis is, maar wat veral in die gemeenskap van die leer gevind word. Dat die antichris in die tempel van God sal sit, het Daniël alreeds (9:7) en Paulus (2 Tess 2:4) vooruit gesê. Ons reken dat die pous van Rome die leier en voorman van daurdie slegte en verfoeilike ryk is.

(Calvyn Institusie IV, ii:12; my vertaling).

Juis omdat daar volgens Calvyn in die Pousdom nog 'kerke' is, blyk die valsheid van die kerk nog soveel te meer. In hulle word 'Christus grotendeels begrawe en verborge, die evangelie word verduister, die vroomheid verdryf en die diens van God byna vernietig; in éen woord, waar alles so verward is, dat daar baie eerder die voorkoms van Babilon as die heilige stad van God vertoon word' (Calvyn Institusie IV, ii:12; my vertaling).

Ruimte ontbreek om nog meer gegewens oor die Reformatore se standpunte oor die ware en valse kerke te gee. Veral John Knox, die Skotse hervormer, is hieroor baie uitgesproke (vgl Dickenson 1949). Dat hierdie valse kerke ook nog in die gestalte van sektes na vore tree, is duidelik in Calvyn se antwoord aan Kardinaal Sadoletus in 1539. Daarin beskryf hy selfs die Rooms-Katolieke Kerk as 'n sekte: 'Van die kant van twee sektes, wat hemelsbreed van mekaar verskil, word ons aangeval. Want watter ooreenkoms is daar uiterlik tussen die pous en die wederdopers...Albei partye hanteer dieselfde aanvalswapen teen ons. Want terwyl hulle die mond vol het oor die Gees, strewe hulle beslis na niks anders nie as om God se Woord te onderdruk en te begrawe nie' (vgl d'Assonville 1988:11).

Teen hierdie historiese agtergrond - verteenwoordigend van 'n algemene konsensus onder die Reformatore - moet die belydenis oor die ware en valse kerke in artikels 28 en 29 van die NGB gesien word.

\section{SKRIFGEGEWENS}

Al die Reformatore het, sonder uitsondering, die onderskeid tussen ware en valse kerk op die Heilige Skrif gegrond. Dit kom hoofsaaklik op die volgende neer: Jesus Christus self het teen die valse kerk gewaarsku (Matt 7:15; 24:5, 24, 25; Joh 10:1w; 16:2vv). By sy afskeid aan die ouderlinge van Efese waarsku die apostel Paulus teen die wrede wolwe, die valse leraars wat die kudde sal verskeur (Hand 20:29). Hy wys ook op die werk van die antichris wat sy plek in die tempel van God sal inneem en voorgee dat hy God is (2 Tess 2:4). Die apostel Petrus vertel van die valse leraars in die kerk 'wat verderflike ketterye heimlik sal invoer' (2 Pet 2:1). Ook die apostel Johannes waarsku teen die antichris en die 'baie antichriste...wat van ons uitgegaan het' (1 Joh 2:18, 19). Hy waarsku ook teen die 'baie valse profete' en roep die ge- 
meente op om die 'geeste' ( $=$ ideologieë) op die proef te stel (1 Joh 4:1). Hierdie voortdurende stryd tussen die ware en valse kerk sien die Reformatore alreeds in die Ou Testament in byvoorbeeld Genesis 3:15, tussen Jakob en Esau, die stryd tussen Dawid en Saul, die worsteling van Jeremia teen die valse profete ensovoorts.

\section{DIE GRONDLIGGENDE VRAAG: WAT IS DIE KERK?}

Die problematiek rondom die ware en valse kerke sal altyd bly voortsleep en die strydvraag oor artikels 28 en 29 sal voortdurend 'n twispunt wees as die primêre vraag oor die wese van die kerk nie beantwoord word nie. Die begrippe 'waar' en 'vals' is tog attribute van die kerk. In kort, wat bedoel die NGB in hierdie artikels met die begrip 'kerk'? Dit is ook nodig om in hierdie verband na die ander artikels van die NGB en ook na die Heidelbergse Kategismus te kyk.

Artikel 27 van die NGB bely' $n$ heilige vergadering of samekoms. Dit is jammer dat die woord 'samekoms' nie in die Afrikaanse vertaling opgeneem is nie. Beide hierdie woorde is in die oorspronklike Franse en Latynse tekste ("congregation et assemblee' in die Franse teks; 'congregatio seu coetus' in die Latynse teks; vgl Bakhuizen van den Brink 1940:112-113). Die twee woorde is nie sinoniem soos wat die vertalers waarskynlik gedink het nie. In die Latyn word 'congregatio' gebruik om na 'n 'vergadering' te verwys en 'coetus' vir ' $n$ 'samekoms'. 'Congregatio' kom van die grondwoord 'grex' wat 'kudde' beteken. 'n Kudde word deur 'n herder, 'n skaapwagter, bymekaargemaak. Hierdie herder kies en roep sy skape. Hy volg 'n sekere beplanning. Daar is 'n 'raadsplan' sodat dadelik gesien kan word waarop dit afstuur. Van hierdie keuse en 'raadsplan' begryp die skape niks nie en daaroor is hulle totaal magteloos. Die fokuspunt hier is dat die herder aktief is en die skape passief. Die herder neem die inisiatief, die herder beplan alles waarom, waar en wanneer, hy roep en laat sy stem hoor, hy versamel en beskerm sy kudde wat hy bymekaarmaak, hy lei hulle na die groen weivelde (vgl Ps 23).

In Sondag 21 van die Heidelbergse Kategismus word dieselfde gedagte gevind. Dit is die Seun van God wat alle inisiatief met sy gemeente neem: Dit is Hy, Jesus Christus, wat die gemeente wat uitverkies is, vergader, beskerm en onderhou.

Die woord 'coetus' ('samekoms') wat in die Afrikaanse vertaling uitgeval het, kom van 'coeo' wat beteken 'om saam te gaan', 'om sigself te versamel', 'om met mekaar te verenig'. Hier is dus sprake van 'n aksie deur die skape van die kudde. Op die daad van die goeie herder wil hulle dus ook saamwees. Die volgorde is uiters belangrik: éérs congregatio en dan daarna coetus: érs Christus se vergaderingswerk, éers die vervulling van God se raadsplan, érs die stem van die Goeie Herder deur sy Woord en Gees en dan gelowiges wat saamkom. Hulle kom byme- 
kaar, want hulle het één Here, één geloof, één doop (Ef 4:5). Die gelowiges het Hom lief, omdat Hy hulle eerste liefgehad het (vgl 1 Joh 4:9).

\section{KERK (GEMEENTE) AS RESULTAAT}

Ná die vergadering deur Christus deur sy Gees en Woord ('congregatio') en die aksie van die gelowiges wat as vrug van hierdie vergaderingswerk tot die kerk saamkom ('coetus'), volg die resultaat, naamlik die 'gemeente wat tot die ewige lewe uitverkies is' (HK Sondag 21). In artikel 28 van die NGB word hierdie gemeente die 'een en dieselfde liggaam' genoem. So word die kerk ook in artikel 29 die liggaam genoem (nêrens verwys die Skrif na die kerk as die openbaring van die liggaam van Christus nie, maar stel dat die kerk die liggaam van Christus is; die idee van 'openbaring van' is 'n geforseerde konstruksie wat in die Dogmatiek ingedra word).

Op aarde is hierdie vergaderingswerk en die samekoms, naamlik die gemeente, nog gemeng met die huigelaars (art 29) en is dit nog onvoltooid. In die hemel is hierdie resultaat wel onvermeng met die huigelaars, maar nog steeds onvoltooid. Dáár wag die lede van die kerk - volgens Openbaring 6-nog op hulle finale volkome verlossing en die voltooiing van Christus se vergaderingswerk ('congregatio') en die saamgaan met hulle broeders ('coetus').

Die uiteindelike resultaat'is, volgens die Gereformeerde doopformulier, die gemeente van die uitverkorenes in die ewige lewe.

\section{SLEGS EEN KERK}

Waar word die begrippe 'waar' en 'vals' toegepas? Geld dit vir die kerk as 'n 'struktuur' (organisasie in geheel; kerkverband) of moet dit alleen op die enkele gemeente toegepas word? Daar mag geen misverstand oor hierdie saak wees nie.

Die Gereformeerde belydenis praat nêrens van verskillende kerke nie, maar slegs van die én 'heilige, algemene, Christelike kerk, die gemeenskap van die heiliges' (Apostoliese Geloofsbelydenis). Die Heidelbergse Kategismus praat ook nie van verskillende gemeentes nie, maar van die énn 'gemeente wat tot die ewige lewe uitverkies is' (Sondag 21). Net so verwys artikel 27 van die Nederlandse Geloofsbelydenis nie na verskillende kerke nie, maar na die 'enige katolieke of algemene kerk, 'n heilige vergadering van almal wat waarlik in Christus glo....'

In artikel 28 van die NGB word daar van dieselfde kerk gepraat as gestel word dat 'daarbuite geen saligheid is nie' en juis daarom is 'almal verplig om daarby aan te sluit en hulle daarmee te verenig om die eenheid van die kerk te bewaar deur hulle almal - as lede van een en dieselfde liggaam - aan sy leer en tug te onder- 
werp'. Artikel 28 gaan verder deur te noem dat dit die 'plig van alle gelowiges [is] om hulle by dié vergadering aan te sluit, waar God dit ook al gevestig het'.

Hier word een van die belangrikste waarhede van die Gereformeerde belydenis oor die kerk aangeraak: Dieselfde 'heilige, algemene Christelike kerk' (Apostoliese Geloofsbelydenis), dieselfde 'heilige vergadering van almal wat waarlik in Christus glo' (art 27 NGB), word deur God op verskillende plekke gevestig (art 28 NGB).

In artikel 29 van die NGB gaan die Belydenis voort deur te waarsku teen die valse kerk. Dit is die enigste ander 'kerk' wat die Belydenis ken: 'Hierdie twee kerke kan maklik uitgeken en van mekaar onderskei word.' Dit kan gedoen word deur die merktekens van die suiwer bediening van die Woord en die sakramente en die handhawing van die kerklike tug. Steeds is hierdie sigbare ware kerk dieselfde katolieke of algemene kerk van artikel 27 wat op verskillende plekke deur God gevestig word (art 28).

\section{WARE EN VALSE KERKE 'EX VERBO DEI'}

Artikel 29 begin met die woorde, 'Ons glo dat ons sorguldig en met groot oplettendheid uit die Woord van God behoort te onderskei watter kerk die ware kerk is....' In die oorspronklike Latynse teks staan daar 'ex Verbo Dei' (vgl Bakhuizen van den Brink 1940:117). In die slot van hierdie teks kom dit selfs baie sterker as in die Afrikaanse vertaling uit. In die oorspronklike Latyn begin die sin met 'Ex his', dit wil sê, hierdie merktekens wat vanuit die Woord na vore kom (vgl Bakhuizen van den Brink 1940:119).

Ook om deur hierdie merktekens die ware van die valse kerk te onderskei, geld die woord van Paulus: 'Die natuurlike mens neem die dinge van die Gees van God nie aan nie; want dit is vir hom dwaasheid en hy kan dit nie verstaan nie, omdat dit geestelik beoordeel word' (1 Kor 2:14). Hierdie 'natuurlike mens', dit wil sê die sondige, ongelowige mens, kan dan ook nie die ware en valse kerk onderskei nie.

\section{WARE EN VAISE KERKE ALLEEN DEUR DIE GELOOF}

Dit is uiters noodsaaklik dat, waar die kennis oor die kerk, juis ook die kennis oor die ware en valse kerke 'uit die Woord van God' verkry word, ook die geloofskarakter van hierdie belydenis beklemtoon word.

Die gevaar bestaan voortdurend dat die Belydenis (die Drie Formuliere) alleen as 'eietydse' geskrifte van die sestiende eeu beskou word en die aktualiteit daarvan alleen vir die tyd van die Reformasie beklemtoon word. Dan word die hele saak van ware en valse kerke gerelativeer. Dat die Belydenis dan 'eietyds' aan die ses- 
tiende eeu sou wees en hoofsaaklik vanuit faktore van destyds verklaar moet word, ontneem nie alleen die aktualiteit vir die twintigste eeu nie, maar tas selfs die geloofskarakter daarvan aan (kyk Visée 1947:153-154, 159-160). Dit moet beklemtoon word dat die Gereformeerde belydenisskrifte juis op die Woord van God gegrondves is - eietyds nie alleen vir die sestiende eeu nie, maar ook vir die twintigste eeu.

So 'n gedeeltelike devaluasie en relativering van die Belydenis vind ons veral ten opsigte van die belydenis oor die ware en valse kerke volgens artikels 28 en 29 van die NGB. Dit kom veral uit in die dogmatiese konstruksie van die leer van die pluriformiteit van die kerk en ook die begrippe 'sigbare en onsigbare kerke'. Hiervolgens openbaar die een onsigbare (ook 'n aanvegbare term!) kerk homself in meer as een sigbare vorm. In die Gereformeerde tradisie was A Kuyper en $\mathbf{H ~ B a - ~}$ vinck voorstanders van hierdie standpunt. Kuyper erken dat hierdie verdeeldheid onder die verskillende kerke nie deur die Belydenis geleer word nie, maar onder die drang van die lewe in die geskiedenis ontstaan het (vgl Kuyper sa, vol 3:234). By Bavinck (1906, vol 4:304) is die pluriformiteit van die kerk'n gevolg van die sonde.

Dit lê voor die hand dat as daar verskillende sigbare 'vorme' of 'gestaltes' van die één sogenaamde onsigbare kerk kan bestaan, dat die kwalifikasie van waar en vals onmiddellik in gedrang kom. Ook hier gaan die devaluasie en die relativering van die Belydenis hom meedöënloos op die geloof aan die bestaan en identifisering van die ware en valse kerke wreek. Kuyper erken dit selfs dat daar nou 'een klove gapen' tussen die Belydenis 'en de overtuiging die zich later onder den drang van het leven gevorm heeft' (Kuyper sa, vol 3:234). Nie die gegewens uit die Skrif oor die ware en valse kerke is nou meer deurslaggewend nie, maar die dogmatiese konstruksie, die pluriformiteit.

\section{WAAR EN VAIS, SIGBAAR OF ONSIGBAAR?}

Die onderskeid 'sigbare en onsigbare kerk' is tipies en spesifiek Protestants. Die Rooms-Katolieke Kerk het nooit die dogma van 'n onsigbare kerk gehandhaaf nie (vgl Küng 1967:363). En weer eens was dit veral Kuyper wat die onderskeid 'sigbare en onsigbare kerk' buitengewoon sterk gepropageer het en hy noem dit 'het principale stuk onzer belijdenis, waarmede onze vaderen tegen Rome zijn opgetreden' (Kuyper 1890:6). Ook Bavinck gee groot aandag aan hierdie onderskeid en wys daarop dat dit Luther was wat die gedagte die eerste keer na vore gebring het (Bavinck 1906, vol 4:311). Calvyn gebruik die term 'onsigbare kerk' ('ecclesia invisibilis') glad nie in die twee eerste uitgawes $(1536,1539)$ van sy Institusie nie, maar eers in 1543, en dan bedoel hy daaronder die totaal van die uitverkorenes wat alleen in 
die oog van God bekend is. Dit is hier belangrik om te noem dat dit nie ' $n$ ander kerk is as die een en dieselfde kerk wat op verskillende plekke gesien kan word nie (Calvyn Institusie IV, i:1-9).

Vir die soveelste keer word die suiwer siening oor ware en valse kerke deur 'n onduidelike terminologie oor die kerk verduister. Die Heilige Skrif en die Gereformeerde belydenis ken nie die terme 'sigbare en onsigbare kerk' nie. Beter sou dit gewees het om te praat van die én kerk wat wel kan gesien word (die geïnstitueerde gemeente) maar tog nie oorsienbaar is nie. As ek byvoorbeeld 'n groep mense voor my in 'n saal of in 'n sportstadion sien, dan sien ek 'n deel van die mensdom. As ek dus nie die hele mensdom kan sien nie, dan is die mensdom tog nie onsigbaar nie. Die is wel onoorsienbaar.

Weer eens: Die begrippe 'waar' en 'vals' kan nie op twee kerke, sogenaamd 'sigbaar' en 'onsigbaar' toegepas word nie. Die ware kerk bly altyd die één heilige algemene kerk soos dit in artikel 27 van die NGB en in die Apostolicum bely word.

\section{IMPLIKASIE VAN KUYPER SE STANDPUNT}

In die beste studie oor Kuyper se kerkbegrip, word sy terminologie oor die ware en valse kerke 'verward en duister' genoem (Van Leeuwen 1946:207). Kuyper fundeer dit nie in die Skrif nie, maar relativeer dit in die werklikheid. Die 'absoluut valse kerk' is vir hom 'n eskatologiese grootheid. In sy Tractaat van de Reformatie der Kerken praat hy van 'die ontzettendste aller deformatiën, die uitioopt in de valsche kerk of de kerk van den Antichrist' (Kuyper 1884:112). Oor die werklikheid hier op aarde handhaaf hy 'gedeeltelijk vervalsche' kerke. Maar die 'absoluut - valsche kerk' is die voltooide openbaring van die kerk, waarin die bose sal poog om die eindoorwinning te vier. Hierdie voltooide kerk vertoef nog volgens Kuyper (1884:112). Teenoor die absolute teenstelling tussen ware en valse kerke, handhaaf Kuyper 'n relatiewe kerkbegrip, "het relatieve niet in de idee, niet in de afgetrokkene, maar in de werklikheid' (Kuyper sa, vol 3:272).

Wat nou van die uitspraak in artikel 28 van die NGB dat 'elkeen verplig is om by die ware kerk aan te sluit' en 'daarom handel almal wat hulle van hierdie ware kerk afskei en nie daarby aansluit nie, in stryd met die bevel van God'? Kuyper maak eenvoudig die sprong om die begrippe 'waar' en 'vals' te vervang met 'suiwer' of 'minder suiwer', of weer 'meer suiwer'. Die ware en valse kerke is by hom geen 'werkelikjheden' nie, maar bestaan slegs in die idee (kyk Kuyper sa, vol 3:272-273 vir die hele betoog). In die werklikheid - volgens Kuyper - word nòg die absoluut ware, nòg die absoluut valse kerk gevind, met ander woorde, daar is geen ware kerk wat aan die idee van die ware kerk ten volle beantwoord en ook geen valse kerk wat 
volkome aan die idee van die valse kerk beantwoord nie. Prakties beteken dit dat die belydenis dat 'almal verplig [is] om daarby [= die ware kerk] aan te sluit' (art 28 NGB), almal dan verplig is om by die relatief suiwerste kerk aan te sluit. Dit is iets totaal anders as wat daar staan.

\section{DIE WARE KERK EN DIE EENHEID VAN DIE KERK}

Artikel 28 bely dat die gelowiges nie alleen die verpligting het om by die ware kerk aan te sluit nie, maar ook om 'hulle daarmee te verenig om die eenheid van die kerk te bewaar deur hulle almal - as lede van een en dieselfde liggaam - aan sy leer en tug te onderwerp'.

Deur by die ware kerk aan te sluit, word die 'eenheid van die kerk bewaar'. Volgens die Latyn moet die unitas ( = eenheid) conservare (= bewaar) word. Hier staan nie dat die eenheid nog verkry of verwerf moet word nie. Sonder die gelowiges se toedoen is die eenheid alreeds daar! Dikwels word gesê: Maak die kerk én. Weer eens is dit nie wat hier staan nie, maar: Die reeds bestaande eenheid moet bewaar word. Die eenheid as die gegewe werklikheid moet gesoek word.

Die verpligting om by die ware kerk aan te sluit, is verbonde aan die absolute feit: Die kerk is één. Hierdie eenheid is in God se raadsbesluit geleë. Die mens kan dit nie verbreek nie. Hy kan dit nie skeur nie. Ter wille van die waarheid (waarin die eenheid geleë is), word die uiterlike strukture soms verbreek. Die Reformatore het byvoorbeeld in die sestiende eeu die eenheid met die RoomsKatolieke Kerk verbreek - ter wille van die ware kerk wat één is!

Wat is dan kerkskeuring volgens hierdie belydenis? Dit is as die kerk nie gebou en gekonstrueer word volgens God se Woord nie; ook as in die uiterlike strukture van 'n pluriformiteit berus word, verflou die roeping om die eenheid te beleef. Die pluriformiteitsteorie is die slaapmiddel vir die drang na die ware kerk (Schilder 1960:94). Deur sy Woord roep Christus egter sy skape saam in een kudde. Hy vergader 'n unica ecclesia, die één kerk, al is hulle ook oor die hele wêreld versprei.

\section{DIE: MERKTIEKENS (NOTAE) SELF}

Die greep van die NGB en ander reformatoriese belydenisskrifte om merktekens (Latyn: notae) vir die ware en valse kerke te konstateer, kom van die begin van die kerkgeskiedenis en dogmageskiedenis af voor (kyk Doekes 1979:298-326). Bellarminus, die teoloog wat die grootste moeite gedoen het om te bewys dat die RoomsKatolieke Kerk die ware kerk is, gee nie minder nie as vyftien merktekens (Honig 1938:717). In die Roomse teologie word daar egter hoofsaaklik op vier merktekens 
gekonsentreer, naamlik eenheid, heiligheid, katolisiteit en apostolisiteit (Honig 1938:717). By die Rooms-Katolieke Kerk het merktekens van die kerk egter nie dieselfde betekenis as by die Protestante nie. Die gereformeerdes maak onderskeid tussen merktekens en eienskappe, maar by die Rooms-Katolieke Kerk word dit geïdentifiseer, bloot omdat die kerk homself as die maatstaf beskou en nie die Woord nie. In die gereformeerde belydenisskrifte is die Woord ook maatstaf vir die kerk.

Die merktekens van die ware en valse kerke wat in artikels 28 en 29 opgesom word, is nie merktekens van 'n statiese, rustende toestand nie, maar van Christus se vergaderende, bewarende en voortgaande werk (Sondag $21 \mathrm{HK}$ ). Dit word ook toegepas op die voortgaande, gehoorsame, aktiewe daad ('coetus') van die gemeente. Dit gaan in hierdie merktekens nie oor wat die ware kerk of valse kerk in sy organisasie of instelling besit nie, maar oor wat daar in die kerk gebeur en wat daar gedoen word. Hierdie merktekens (notae) is (Bakhuizen van den Brink 1940:115117):

- die pura evangelii praedicatione utatur (die suiwer prediking van die Evangelie);

- die sicera sacramentorum, ex Christi praescripto, administratione uti (die suiwer bediening van die sakramente soos Christus dit ingestel het);

- disciplina ecclesiastica, ut vitia comigantur, obtineat (handhawing van die kerklike tug sodat die sondes gestraf word).

Baie belangrik is die gebruik van die woorde utatur ('gebruik') en obtineat ('handhaaf, 'in stand hou'). Dit gaan hier oor 'n gewoonte, 'n reël wat in gebruik is en nie slegs 'n enkele, ongewone of 'toevallige', insidentele gebeurtenis nie. Om dit prakties te stel: nie so nou en dan 'n suiwer preek of enkele kere wat die sakramente suiwer bedien sou word nie, maar wat is die voortgaande gebruik?

Die merktekens van die ware kerk is nie slegs dat die kerk God se Woord en die sakramente besit en dat die tug wel daar bestaan nie, maar of al hierdie dinge suiwer volgens God se Woord bedien word.

Dit kan gebeur - en dit gebeur inderdaad - dat die valse kerk sowel die Woord as die sakramente en die tug besit. Besit daarvan is nog nie die finale merktekens nie, maar of Woord, sakramente en tug suiwer bedien word. Die Woord kan byvoorbeeld gebruik word om valse ideologieë te propageer, die sakramente kan bygelowig hanteer word en die tug kan op 'n wêreldse wyse onbybels toegepas word!

\section{DIE MERKTEKENS VAN DIE VALSE KERK}

Opvallend noem die Belydenis in artikel 29 die merktekens van die valse kerk, maar nie die merktekens van die lede van hierdie 'kerk; nie. By die ware kerk word dit 
uitdruklik bely: 'Vervolgens, aangaande die lidmate van die kerk: Ons kan hulle uitken aan die kenmerke van die Christene, naamlik hulle geloof dat hulle die enigste Verlosser Jesus Christus aangeneem het en dat hulle daarna die sonde ontvlug, die geregtigheid najaag, die ware God en hulle naaste liefhet, nje na regs of links afwyk nie en hulle sondige natuur met sy werke kruisig, ens.'

Hiermee het die Belydenis dit uitgespreek dat daar nog kinders van God in die valse kerk kan wees. So het die Reformatore ook bely. Hoe skerp hulle ook al oor die valse Roomse kerk 'n oordeel uitgespreek het - oor die persone as lede van daardie kerk het hulle dit nie gedoen nie (Feenstra 1947:377).

By die valse kerk is die kernpunt weer eens die Woord van God: 'Dit skryf aan homself en sy besluit meer mag en gesag toe as aan die Woord van God, ens.' Die skeiding is tussen Skrifgesag of kerkgesag - gehoorsaamheid aan die Woord of ongehoorsaamheid daaraan.

\section{'DAAR STAAN GESKRYWE'}

Alles wat oor die kerk in artikels 28 en 29 van die NGB gesê word, geld vir die één kerk. Hierdie heilige, algemene Christelike kerk mag van sy instituut en sy institueringsplig nooit losgemaak word nie. Omdat die instelling en die opbou van die werklike plaaslike gemeente nou eenmaal tot die essensiële bestaan van die kerk behoort, mag die belydenis in die één ware Christelike kerk deur die eeue en oor die hele wêreld nooit vergeet word nie. By die vergadering ('congregatio') hoort onlosmaaklik die samekoms ('coetus') (Feenstra 1947:385).

Hoe groot die betekenis van die eksistensiële bestaan as 'n werklikheid in die menslike lewe ook al is, die normatiewe krag is en bly altyd: 'Daar staan geskrywe.' Daarby het die Woord met sy dinamiese krag (Rom 1:16) wat nooit van die werking van die Heilige Gees geskei kan word nie, die laaste sê oor die waarheid en die valsheid van die kerk. Dit bring ook die finale skeiding tussen die ware kerk en die valse kerk - hier werklik konkreet in my omgewing.

Die merkteken van die ware kerk is sy aktiewe gehoorsaamheid aan die Woord van God.... Die merkteken van die valse kerk is sy aktiewe ongehoorsaamheid aan die Woord van God....

\section{Literatuurverwysings}

Bakhuizen van den Brink, J N 1940. De Nederlandsche Belijdenisschriften; vergelijkende teksten. Amsterdam: Holland.

Bavinck, H 1906. Gereformeerde dogmatiek. 4 dele. Kampen: Bos. 
d'Assonville, V E 1988. Observations on Calvin's Responsio to Cardinal Sadoletus's letter to the Genevans, in Calvinus servus Christi. Budapest: Presseabteilung des Ráday-Kollegiums.

.-. 1974. Calvyn verdedig sy stad. Potchefstroom: Pro Rege.

Dickinson, W C 1949. John Knox's history of the Reformation in Scotland, 2 vols. London: Thomas Neison \& Sons.

Doekes, L 1979. Credo - Handboek voor de Gereformeerde symboliek. Amsterdam: Ton Bolland.

Feenstra, J G 1947. Onze geloofsbelijdenis. Kampen: Kok.

Heidelbergse Kategismus 1987. Kaapstad: NG Kerkuitgewers.

Küng, H 1967. De Kerk. Antwerpen: Paul Brand.

Honig, A G 1938. Handboek van de Gereformeerde dogmatiek. Kampen: Kok.

Kuyper, A sa. De gemeene gratie. 3 dele. Kampen: Kok.

--- 1884. Traktaat van de Reformatie der kerken. Amsterdam: Höveker \& Zoon.

--- 1890. Separatie en Doleantie. Amsterdam: Wormser.

Luther, M 1826-1857. Sämmtliche Werke. 67 dele. Erlangen: Plochmann. (Ook bekend as 'Erlangen Ausgabe'.)

Nederlandse Geloofsbelydenis 1987. Kaapstad: NG Kerkuitgewers.

Polman, A D R sa. Onze Nederlandsche Geloofsbelijdenis. 4 dele. Franeker: Wever. Schilder, K 1960. De Kerk. 3 dele. Goes: Oosterbaan \& Le Cointre.

--- 1950. Christelijke religie - Nederlandsche Geloofsbelijdenis. Ongepubliseerde klasdiktate, Kampen.

Sizoo, A 1956. Johannes Calvijn - Institusie. 3 dele. Delft: Naamloze Vennootschap Meinema.

Van Leeuwen, P A 1946. Het kerkbegrip in de theologie van Ahraham Kuyper. Franeker: Wever.

Visee, G 1947. De ware en de valsche kerk. Dienst 9-12. (Maandblad voor Ouderlingen en Diakenen.) 